\title{
Precipitation dynamics and chemical properties in tropical mountain forests of Ecuador
}

\author{
R. Rollenbeck ${ }^{1,2}$, P. Fabian ${ }^{2}$, and J. Bendix ${ }^{1}$ \\ ${ }^{1}$ University of Marburg, Faculty of Geography, Laboratory for Climatology and Remote Sensing (LCRS), Germany \\ ${ }^{2}$ Institute for Bioclimatology and Immission Research, Technical University of Munich, Germany
}

Received: 28 June 2005 - Revised: 6 October 2005 - Accepted: 18 October 2005 - Published: 9 January 2006

\begin{abstract}
Terrestrial ecosystems in southern Ecuador are strongly affected by interannual climate variations. This holds especially true for the episodic El Niño events, which cause above-normal precipitation in the coastal region of Ecuador and below normal values in the eastern provinces of the Amazon basin (Bendix, 1999). For the transitional zone between these two extremes, which consists mainly of the andean slopes and larger interandean basins the effect on interannual climate variability is not well known.

The PREDICT project monitors regional climate in the provinces of Loja and Zamora-Chinchipe $\left(4^{\circ} \mathrm{S} / 79^{\circ} \mathrm{W}\right)$, where a strong gradients of precipitation are observed. Between the eastern slopes of the Cordillera Real and the dry valley of Catamayo, which are only $70 \mathrm{~km}$ apart, rain totals drop from over $4000 \mathrm{~mm}$ to only $300 \mathrm{~mm}$ per year. These two extremes represent the both sides of the Andean mountain chain and are completely covered by the study area, which is $120 \mathrm{~km}$ in diameter. Methods used are a combination of point measurements (climate stations) and remote sensing devices (weather radar, satellite imagery), which enable a high-resolution real-time observation of rain distribution and underlying processes. By this, ideal conditions are given to monitor a potential shift of the transition zone between below-average and above-average rainfall situated in this region, if another ENSO-anomaly occurs. Furthermore variability of atmospheric nutrient inputs is analysed within the scope of the project, to assess further impacts on this ecosystem.
\end{abstract}

\section{Introduction}

Southern Ecuador is one of the regions most impacted by ENSO-variability. Whereas coastal areas in south Ecuador and northern Peru suffer from heavy precipitation and associated flooding events, the Amazon Basin is known to have

Correspondence to: R. Rollenbeck

(rollenbe@staff.uni-marburg.de) prolonged dryness, as was observed especially in 1998 (Rollenbeck, 2002). The transition zone between these two differing patterns is formed by the Andean Cordillera, which in large parts of South America is formed by two more or less parallel mountain chains. In the region of Loja, this topograpic scheme is modified; here, a distinct depression in the average altitude of the chains is observable and the regular structure is interrupted by many perpendicular valleys cutting deeply into the Cordillera. Hence, this region also acts as a natural connection between the humid Amazon lowlands and the semi-arid to arid coastal areas.

The PREDICT project was implemented to determine local variability and processes leading to the extreme heterogeneity of precipitation input in tropical mountain forests. As is well known, strong altitudinal gradients exist in these ecosystems (Weischet, 1969; Bruijnzeel, 2000). But there are several other factors affecting the formation of spatial differences of precipitation, such as exposition of mountain chains to prevailing winds, variations of cloud condensation level and of course many dynamic processes like local wind phenomena as foehn (dry leeward winds) and the mass elevation effect. To understand the interaction of these processes, a combination of local observation points and remote sensing is needed.

\section{Methods}

The central research area of the project is located some $15 \mathrm{~km}$ east of the provincial capital of Loja, on the eastern slope of the Cordillera Real, the main ridge of the Andes in this region. Here, conventional climate stations are operated in a dense network and with high temporal resolution (Fig. 1, right). This enables the precise assessment of important variables like altitudinal gradients of rain and fog precipitation as well as cloud levels. Also, the input of inorganic chemical compunds through precipitation is analysed, to determine contributions to the local nutrient balance (Rollenbeck et al., 2004). 


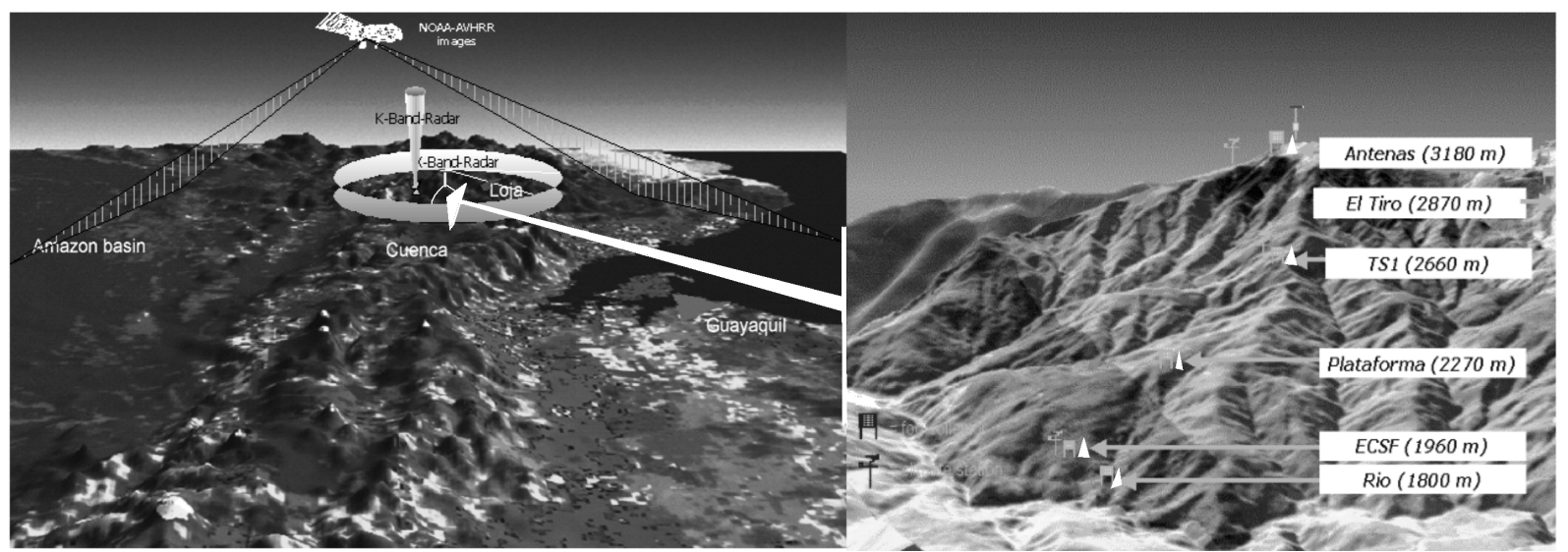

Fig. 1. 3-D-View of the study region in the south of Ecuador and the central research area. The white trangles show the position of rain and fog sampling sites.

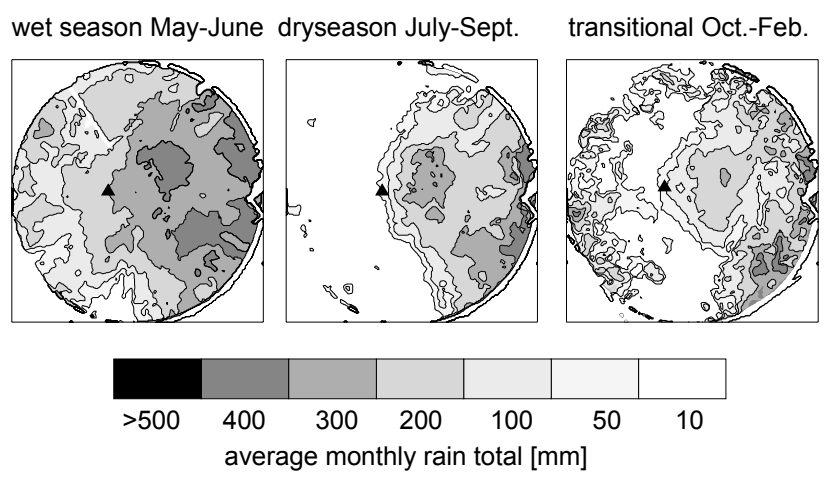

Fig. 2. Rainfall distribution within the study region $(120 \times 120 \mathrm{~km})$ derived from radar data for the years 2002 and 2003. The triangle marks the location of the provincial capital Loja.

To complement this detailed analysis, a weather radar is installed at the highest peak of the study area, covering a range of $60 \mathrm{~km}$ and giving five-minute totals of the rain distribution in the wider study region, with a pixelwidth of $500 \mathrm{~m}$ (Rollenbeck and Bendix, 2004). This enables the analysis of regional rain generating processes, because the whole zone from the humid eastern lowlands via the highest andean peaks to the western coastal hills is covered (see Fig. 1, left).

Additionally, the project makes intensive use of NOAAAVHRR (Advanced very high resolution radiometer) satellite imagery and has adopted a cloud detection scheme to determine frequency and distribution of cloudiness for all of Ecuador. Furthermore variables like cloud top-altitude and liquid-water path can be derived (Bendix et al., 2004).

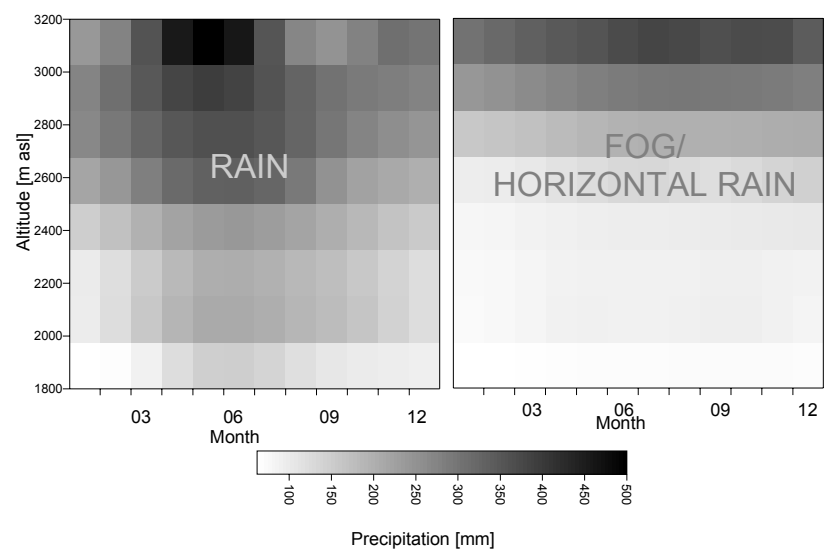

Fig. 3. Height/time section of monthly totals of rain and fog/horizontal rain in the central research area.

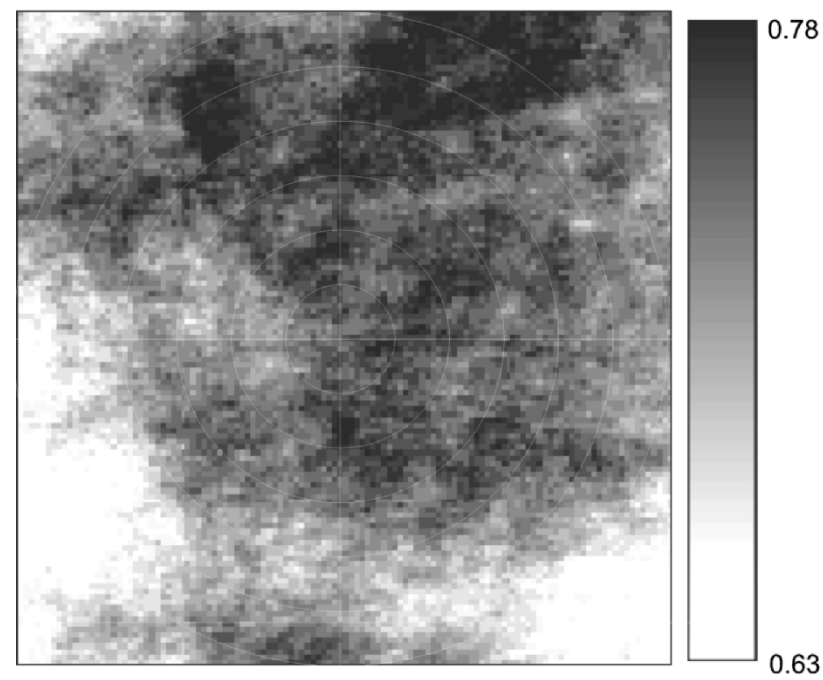

Fig. 4. Relative cloud frequency derived from satellite images (NOAA-AVHRR) for the study region. Range circles for every $10 \mathrm{~km}$ of distance from the radar location are shown. 


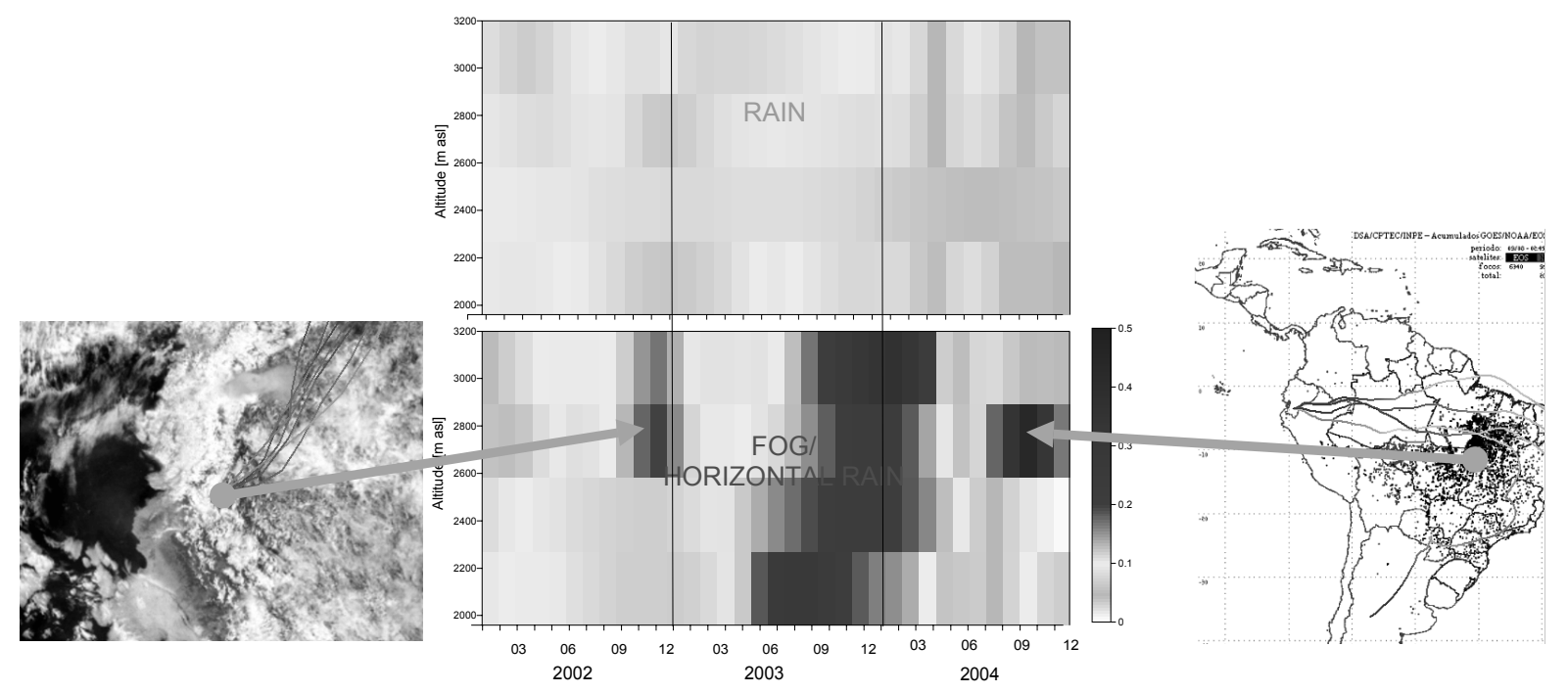

Fig. 5. Altitudinal variations 2002-2004 of ionic load in rain and fog water as observed in the central research area. Sources end evidence by backward trajectories is shown for two peak-input episodes. Left: Eruption of El Reventador (3 November 2002), right, Firepixels in September 2004 as detected by NOAA and GOES satellites (INPE, Brasil) and time synchronous trajectories.

\section{Results}

The data obtained so far, indicate a clear seasonal variation of precipitation input for the wider study region. Main rainy season is from April to August, whereas a secondary less pronounced peak occurs in some years in December. Radarderived rain distributions show that this seasonality is different for the eastern and western half of the region. Fig. 2 shows monthly totals of rainfall for the whole range covered by the radar (Fig. 1, left). The eastern half of the circle consists of the very humid eastern andean slope, with high rainfall in almost all months. In the western half the rainy season observed in the central study area, is replaced by a bimodal pattern, showing pronounced dryness in July to September.

The altitudinal gradients show details of the seasonality within the central research area. The lower parts show the previously mentioned peak in June-July, while the upper parts above $2600 \mathrm{~m}$ have maximum rain fall earlier in April to May (Fig. 3). A secondary maximum can be observed at least for the highest station in November. The right panel in Fig. 3 shows the potential input of fog and winddriven rain, which is registered by mesh collectors of $1 \mathrm{~m}^{2}$ at the climate stations (also Fig. 1 right). Maximum input is observed in July and August, when highest wind speeds are measured.

The altitudinal gradient is non-linear for both precipitation types. On average it increases by $230 \mathrm{~mm} / 100 \mathrm{~m}$ for rain and $240 \mathrm{~mm} / 100 \mathrm{~m}$ for fog. But the highest increase is always observed in the higher portions of the study site, between 2600 and $3200 \mathrm{~m}$. This coincides with the visually observed condensation level of 2700 to $3100 \mathrm{~m}$.

The rainfall distribution observed (Fig. 2) is also represented in the horizontal extent of cloudiness. Analysis of 2 years of almost daily satellite images from the AVHRR sensor enabled us to calculate cloud frequency for the region covered by the weather radar. Figure 4 shows the relative values of cloudiness. The barrage effect of the main andean chain is clearly visible, as well as the low cloudiness due to "foehn"-effects in the valleys southwest of the highest ridges. A modification of this pattern is very probable, if El Niño affects the regional atmospheric flows.

As rainfall is the most important source for input of inorganic nutrients in the ecosystem of tropical mountain forest, this study and the wealth of data was also used to assess the atmospheric contribution to the local nutrient balance. Hence, all precipitation samplers are also used to take weekly water samples, that are subsequently analysed for the major ions, as there are: $\mathrm{Na}+, \mathrm{K}+, \mathrm{NH}_{4}^{+}, \mathrm{Mg}^{2+}, \mathrm{Ca}^{2+}, \mathrm{Cl}$, $\mathrm{NO}_{3}^{-}, \mathrm{SO}_{4}^{2-}$ and $\mathrm{PO}_{4}^{3}$. In general, atmospheric input is low, but some episodic events show concentrations, that were unknown for tropical environments and may reach levels only observed in industrialized countries. This applies especially for $\mathrm{S}$ - and $\mathrm{N}$ - species, but also $\mathrm{Ca}$ and $\mathrm{Na}$, sometimes show unusal high levels. To find out if there are regular phenomena controlling these inputs, the altitudinal gradient was investigated for seasonal variations (Fig. 5). Though the total ionic load exhibits some interannual variations, a distinct seasonal pattern is not recognizable. The episodic events are centered at different times of the year and also occur in different altitudes. This holds especially true for the concentrations in fogwater. To determine possible sources for these elevated concentrations, we used backward-trajectories (Stohl and Trickl, 1999) to determine generalized flow patterns for the regions. By overlaying these data with maps of biomassburning, a strong evidence resulted, that the immissions are caused by heavy forest fires, which are mainly located in Brazil (Fabian et al., 2005) (see Fig. 6). But natural sources play a role too: High loads in November 2002 could be explained by airmasses that passed the recently erupted volcanoe El Reventador. 


\section{Conclusions}

Regional climate variability in the southern ecuadorian Andes is mainly controlled by topograpic variables, climatological processes and the interaction of both. This kind of dynamics can not be detected by the conventional station network, which neither has the required density nor the capability to observe dynamic processes. Although in the last few years since 1999 no strong deviations from normal ENSOconditions could be observed, yet this study may help to assess the potential impact of larger-scale oscillations like El Niño on terrestrial ecosystems in the south of Ecuador, because it is situated at the pivotal point between two opposing impacts of this climatic oscillation. Furthermore, identification of nutrient inputs and variations in the nutrient balance may result in a broader understanding of the ecosystem impact, because not only rainfall is affected, but also other consequences of atmospheric oscillations are probable.

The study will be continued until 2009 and will probably be able to monitor larger variations of ENSO in the coming years.

Edited by: P. Fabian and J. L. Santos

Reviewed by: two anonymous referees

\section{References}

Bendix, J.: Precipitation Dynamics in Ecuador and Northern Peru during the 1991/92 El Niño- a remote sensing perspective, Int. J. Rem. Sens. H., 21, 533-548, 1999.

Bendix, J., Rollenbeck, R., and Palacios, E.: Cloud classification in the Tropics - a suitable tool for climateecologicalstudies in the high mountains of Ecuador, Int. J. Rem. Sens., 25, 21, 45214540, 2004.

Bruijnzeel, L. A.: Hydrology of tropical montane cloud forests: A Reassessment, Land Use and Water Resources Research, 1, 1.1$1.18,2000$

Fabian P., Kohlpaintner M., and Rollenbeck, R.: Biomass burning in the Amazon - fertilizer for the mountaineous rain forest in Ecuador, Environm. Sci. Pollut. Res., 12, 5, 290-296, 2005.

Rollenbeck, R.: Wasser- und Energiehaushalt eines neotropischen Tieflandregenwalds, Mannh. Geogr. Arb., 55, 173 pp., 2002.

Rollenbeck, R., Bendix, J., Fabian, P.: Spatial and temporal dynamics of atmospheric water- and nutrient inputs in tropical mountain forests of southern Ecuador, Proceedings of the 2nd Int. Conference on tropical montane cloud forests, Waimea, Hawaii, in press, 2004.

Rollenbeck, R. and Bendix, J.: Experimental calibration of a costeffective X-band weather radar for climate-ecological studies in southern Ecuador, Atmos. Res., in press, 2004.

Weischet, W.: Klimatologische Regeln zur Vertikalverteilung der Niederschläge in Tropengebirgen, Die Erde $100 \mathrm{Jg}$. H., 2-4, 287-310, 1969. 